\title{
ANALISIS KINERJA KEUANGAN PT CIPUTRA DEVELOPMENT TBK (CTRA) SETELAH PENERBITAN DANA INVESTASI REAL ESTAT (DIRE)
}

\author{
Martin Teguh Wibowo \\ Program Studi Magister Manajemen Universitas Tarumanagara \\ martin.teguh@gmail.com
}

\begin{abstract}
Real Estate Investment Trust is known in Indonesian regulation as Dana Investasi Real Estat (DIRE). Many Indonesian listed developers are still not interested in DIRE as one of financing alternatives. This research aims to analyze the 2017 financial performance of PT Ciputra Development Tbk (CTRA) as a result of issuance of DIRE in terms of (i) funds received from DIRE issuance;(ii) dividend received from DIRE and (iii) its solvency ratios. The result of the research can be useful as (i) an input for management of CTRA that issuance of DIRE can be beneficial in terms of financial and (ii) a reference for investors for diversification in their investments. The method of this research is qualitative descriptive. The research used 2017 audited financial data for recurring income and its related expenses, fair value of recurring assets and some assumptions such as: $51 \%$ ownership of CTRA in DIRE, fees related to DIRE supporting institutions and issuance costs, as a basis for financial calculation of DIRE issuance. The result found that CTRA have (i) fresh fund from issuance of DIRE of Rp 3,7 trillion ; (ii) dividend from DIRE in 2017 of Rp 242 billion; and (iii) healthier solvency ratios after DIRE issuance i.e. lower DER and Debt ratio. The conclusion of this research is that CTRA have improved financial performance i.e. lowered solvency ratios and steady dividend streaming from DIRE every year. CTRA will have room for growth in the future to develop new projects.
\end{abstract}

\begin{abstract}
Abstrak:
Real Estate Investment Trust (REIT) dikenal di peraturan di Indonesia sebagai Dana Investasi Real Estat (DIRE). Banyak perusahaan pengembang yang terdaftar di Indonesia masih belum tertarik pada DIRE sebagai salah satu sumber alternatif pembiayaan. Penelitian ini bertujuan untuk menganalisis kinerja keuangan tahun 2017 atas PT Ciputra Development Tbk (CTRA) dari penerbitan DIRE berupa (i) dana yang diterima dari penerbitan DIRE, (ii) dividen yang diterima dari DIRE dan (iii) rasio solvabilitasnya. Hasil penelitian dapat berguna sebagai (i) input untuk manajemen CTRA bahwa penerbitan DIRE dapat menguntungkan dalam hal keuangan dan (ii) referensi bagi investor untuk melakukan diversifikasi atas investasinya. Metode penelitian ini adalah kualitatif deskriptif. Penelitian ini menggunakan data keuangan yang diaudit untuk tahun 2017 untuk recurring income dan biaya-biaya terkait, nilai wajar dari aset-aset recurring dan sejumlah asumsi yaitu kepemilikan CTRA di DIRE sebesar 51\%, biaya-biaya terkait lembaga penunjang DIRE dan biaya penerbitan, sebagai dasar untuk melakukan perhitungan keuangan penerbitan DIRE. Hasilnya adalah CTRA mendapatkan (i) dana segar dari penerbitan DIRE sebesar Rp 3,7 triliun; (ii) dividen dari DIRE sebesar Rp 242 miliar pada tahun 2017; dan (iii) rasio solvabilitas yang lebih sehat setelah penerbitan DIRE yaitu menurunnya DER dan Debt ratio. Kesimpulan dari penelitian ini adalah CTRA memiliki kinerja keuangan yang meningkat yaitu menurunnya rasio solvabilitas dan arus dividen yang stabil dari DIRE setiap tahunnya. CTRA akan memiliki ruang tumbuh yang lebih besar di masa depan untuk mengembangkan proyek-proyek baru.
\end{abstract}

Keywords: Dana Investasi Real Estat (DIRE), Real Estate Investment Trusts (REITs), Recurring income 


\section{PENDAHULUAN}

Kurang berkembangnya DIRE di Indonesia cukup disayangkan mengingat instrumen investasi ini memiliki beberapa manfaat dengan melakukan penerbitan DIRE seperti peningkatan pembangunan sektor properti, peningkatan pembangunan infrastruktur serta pembangunan sektor pariwisata. Manfaat juga bisa didapatkan dari perusahaan yang menjual aset melalui penerbitan DIRE adalah di antaranya (i) recycle capital, yakni dana yang diperoleh dari DIRE ini dapat digunakan untuk ekspansi atau membangun properti selanjutnya dan (ii) DIRE juga memperkuat rasio-rasio solvabilitas yakni dana yang diperoleh dari DIRE dapat digunakan untuk melunasi utang-utang terkait pembayaran properti.

Belum banyaknya penerbitan DIRE oleh perusahaan pengembang di Indonesia dan pertanyaan yang mengusik peneliti adalah apakah karena kinerja keuangan yang diperoleh setelah penerbitan DIRE dirasakan kurang cukup untuk meningkatkan kinerja keuangan perusahaan pengembang tersebut, membuat peneliti tertarik untuk melakukan penelitian atas penerbitan DIRE ini mengenai analisis kinerja keuangan bagi perusahaan pengembang atau property developer yang menerbitkan DIRE tersebut.

Penulis memilih salah satu emiten perusahaan pengembang papan atas yang terdaftar di Bursa Efek Indonesia yaitu PT Ciputra Development Tbk (CTRA) untuk dilakukan analisis kinerja keuangannya. PT Ciputra Development Tbk (CTRA) memiliki banyak aset yang menghasilkan recurring income seperti mal, hotel, dan sewa perkantoran. Ini menjadi kriteria perusahaan pengembang yang dapat melakukan penerbitan DIRE karena memiliki banyak aset yang menghasilkan recurring income. Berdasarkan laporan keuangan audit PT Ciputra Development Tbk tahun 2017, recurring income nya berjumlah $\mathrm{Rp}$ 1,7 triliun terdiri dari pendapatan dari mal, hotel, rumah sakit, sewa kantor, lapangan golf dan lainnya. Pendapatan yang hampir stabil di sekitar Rp 1,7 triliun ini dapat menjadi potensi besar bagi penerbitan DIRE. Dana dari penerbitan DIRE tersebut dapat digunakan untuk membayar pinjaman bank yang dimiliki Perusahaan dan atau untuk ekspansi sehingga dapat meningkatkan kinerja keuangan Perusahaan.

\section{TELAAH KEPUSTAKAAN}

\section{Pengertian Real Estate Investment Trusts (REITs) atau Dana Investasi Real Estat (DIRE)}

Di Indonesia, REITs dikenal dengan nama Dana Investasi Real Estat (DIRE). Berdasarkan Peraturan Otoritas Jasa Keuangan Nomor 19/POJK.04/2016 tentang Pedoman Bagi Manajer Investasi dan Bank Kustodian Yang Melakukan Pengelolaan Dana Investasi Real Estat Berbentuk Kontrak Investasi Kolektif tanggal 16 Maret 2016, pengertian dana investasi real estat (DIRE) adalah wadah yang dipergunakan untuk menghimpun dana dari masyarakat pemodal untuk selanjutnya diinvestasikan pada aset real estat, aset yang berkaitan dengan aset yang berkaitan dengan real estat, dan/atau kas dan setara kas. Real estat adalah tanah secara fisik dan bangunan yang ada di atasnya. Aset yang berkaitan dengan real estat adalah efek perusahaan real estat yang tercatat di Bursa Efek dan/atau diterbitkan oleh perusahaan real estat. DIRE di Indonesia berbentuk Kontrak Investasi Kolektif (KIK). Pengertian Kontrak Investasi Kolektif ("KIK") berdasarkan Undang-Undang Nomor 8 Tahun 1995 tentang Pasar Modal adalah kontrak antara Manajer Investasi dan Bank Kustodian yang mengikat pemegang unit penyertaan dimana Manajer Investasi diberi wewenang untuk mengelola portofolio investasi kolektif dan Bank Kustodian diberi wewenang untuk melaksanakan penitipan kolektif. DIRE berbentuk Kontrak Investasi Kolektif dapat 
melakukan penawaran umum atas unit penyertaannya kepada masyarakat pemodal. DIRE juga dapat mencatatkan unit penyertaannya di Bursa Efek.

\section{Skema Transaksi DIRE}

DIRE berbentuk Kontrak Investasi Kolektif dapat menginvestasikan dananya pada real estat dengan atau tanpa menggunakan Special Purpose Company. Skema tanpa menggunakan Special Purpose Company dikenal dengan nama skema kepemilikan langsung. Skema transaksi DIRE tanpa menggunakan Special Purpose Company atau kepemilikan langsung belum dimungkinkan karena Kontrak Investasi Kolektif (KIK) tidak dapat memiliki tanah. Berdasarkan pasal 4 UU No. 5 Tahun 1960 tentang Peraturan Dasar Pokok-Pokok Agraria hanya badan hukum dan perseorangan yang dapat memiliki tanah. Dalam hal skema transaksi DIRE menggunakan Special Purpose Company atau kepemilikan tidak langsung maka Special Purpose Company wajib mendistribusikan seluruh hasil investasi kepada DIRE dan pihak lain secara proporsional. Skema transaksi DIRE dengan kepemilikan tidak langsung dapat digambarkan sebagai berikut:

A. Aliran Kas Saat Perolehan Bangunan/Gedung

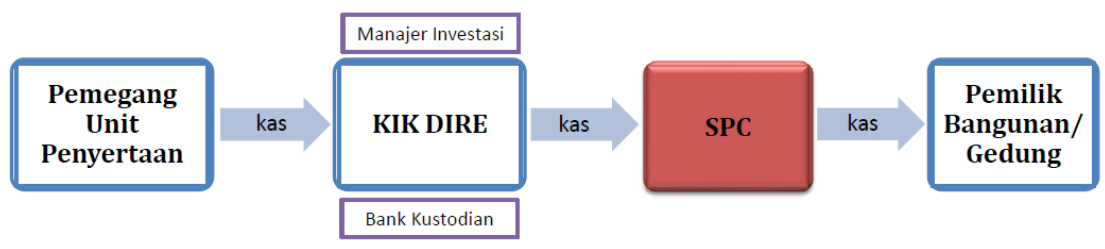

\section{B. Aliran Kas Atas Hasil Dari Bangunan/Gedung}

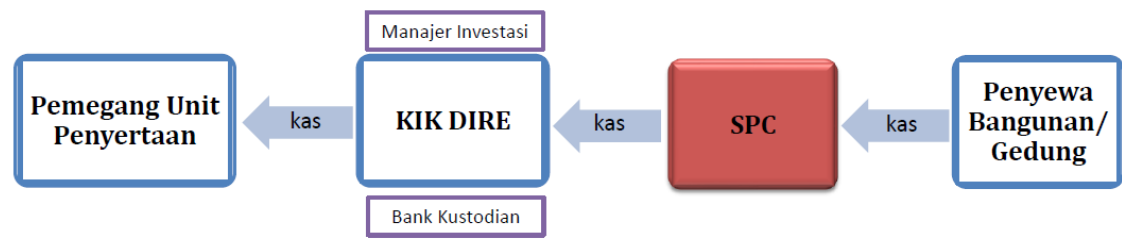

\section{Sumber: Otoritas Jasa Keuangan, Presentasi Dana Investasi Real Estat, 28 November 2016)}

\section{Perkembangan DIRE di Indonesia}

Perkembangan DIRE di Indonesia di Indonesia hanya baru ada satu DIRE yaitu DIRE Ciptadana Properti Ritel Indonesia (DIRE Ciptadana) dengan kode efek XCID dan dicatatkan di Bursa Efek Indonesia pada tanggal 1 Agustus 2013. Total unit penyertaan adalah sebanyak 4.000.000.000 unit. Aset portofolio utama DIRE Ciptadana ini adalah Solo Grand Mall (SGM), sebual mal retail yang berlokasi di kota Solo.

\section{METODOLOGI PENELITIAN}

Data yang digunakan dalam penelitian ini merupakan data sekunder yang didapat dari berbagai sumber yaitu website PT Ciputra Development Tbk, laporan tahunan dan laporan keuangan yang diaudit untuk tahun 2017 PT Ciputra Development Tbk, website Bursa Efek Indonesia, website Bank Indonesia, prospektus DIRE Ciptadana Properti Ritel Indonesia, berita-berita baik media cetak maupun media elektronik. Periode yang akan dilakukan penelitian adalah tahun buku 2017. Selain itu pengumpulan data dan informasi dari beberapa sumber lainnya seperti buku-buku yang berhubungan dengan DIRE atau REITs dan juga berita-berita baik media cetak maupun media elektronik yang berhubungan dengan penelitian ini. Data yang digunakan adalah data keuangan tahun buku 2017 yang telah diaudit, data 
keuangan perihal Mal Ciputra Jakarta, Mal Ciputra Semarang, Mal Lotte Shopping Avenue, Hotel Ciputra Jakarta, Hotel Ciputra Semarang, Hotel Raffles dan perkantoran DBS Tower.

Metode analisis yang digunakan dalam penelitian ini adalah metode analisis data secara kualitatif deskriptif. Penelitian ini menggunakan data keuangan yang diaudit tahun 2017 untuk data recurring income dan biaya-biaya terkaitnya, nilai pasar atau wajar dari aset-aset yang dialihkan dari CTRA ke DIRE yang berasal dari Laporan Kantor Jasa Penilai Publik (KJPP), dan sejumlah asumsi yang digunakan seperti (i) kepemilikan CTRA di DIRE sebesar 51\%, (ii) biaya-biaya terkait lembaga penunjang DIRE yaitu manajer properti, bank kustodian dan manajer investasi, dan (iii) biaya-biaya terkait penerbitan DIRE, sebagai dasar untuk melakukan analisis kinerja keuangan CTRA setelah penerbitan DIRE. Kinerja keuangan yang dianalisis adalah (i) berapa estimasi dana yang diperoleh oleh CTRA sebagai penerbit DIRE berbentuk KIK untuk digunakan oleh Perusahaan baik untuk ekspansi, membiayai proyek yang sedang berlangsung atau membayar lunas utang-utangnya, (ii) berapa besar recurring income yang akan didapat CTRA dari kepemilikannya di DIRE Ciputra dalam bentuk dividen; dan (iii) bagaimana rasio-rasio solvabilitas CTRA setelah IPO DIRE Ciputra. berikut:

Informasi, data-data dan asumsi yang digunakan dalam analisis ini adalah sebagai

- Data keuangan yang digunakan adalah angka keuangan yang telah diaudit untuk tahun 2017. DIRE-KIK untuk CTRA menggunakan nama DIRE Ciputra. Skema DIRE-KIK untuk CTRA menggunakan skema kepemilikan tidak langsung yaitu melalui Special Purpose Company. Tidak ada penamaan untuk Special Purpose Company ini. Analisis ini akan menyebut Special Purpose Company dengan SPC.

- Aset yang dialihkan oleh CTRA ke DIRE Ciputra melalui Special Purpose Company terdiri dari 7 aset yaitu sebagai berikut : (i) aset pusat niaga yaitu Mal Ciputra Jakarta, Mal Ciputra Semarang dan Mal Lotte Shopping Avenue; (ii) aset hotel yaitu Hotel Ciputra Jakarta, Hotel Ciputra Semarang dan Hotel Raffles; (iii) aset kantor yaitu gedung perkantoran DBS Tower.

- Harga transaksi ketujuh aset tersebut yang dialihkan ke SPC/DIRE Ciputra menggunakan nilai pasar yang wajar dari Kantor Jasa Penilai Publik (KJPP) yaitu sebesar Rp 9,4 Triliun.

- $\quad$ CTRA juga menjadi pemegang unit penyertaan di DIRE Ciputra sebanyak 51\% dan sisanya $49 \%$ akan dilepas ke masyarakat atau publik melalui mekanisme penawaran umum. CTRA tetap memegang kontrol atas DIRE Ciputra dengan menjadi pemegang unit mayoritas.

- Besarnya biaya manajer investasi, bank kustodian dan manajer properti akan menggunakan benchmark DIRE Ciptadana Properti Ritel Indonesia karena di Indonesia baru ada satu DIRE. Oleh karena itu, untuk kepentingan analisis ini, penelitian ini akan menggunakan skema biaya untuk ketiga konsultan tersebut sebagai berikut: (i) biaya manajer investasi terdiri dari: biaya tetap per tahun sebesar 0,3\% dari total aset; biaya kinerja per tahun sebesar 3\% dari net property income setelah pajak; (ii) biaya bank kustodian per tahun sebesar 0,10\% dari Nilai Aktiva Bersih (NAB); (iii) biaya manajer properti per tahun sebesar $1 \%$ dari pendapatan real estat dikurangi dengan biaya-biaya real estat.

- Biaya initial public offering (IPO menggunakan estimasi 3\% dari total dana IPO (porsi 49\% kepemilikan masyarakat). Biaya ini umumnya terdiri dari biaya komisi bank atau underwriter, biaya konsultan seperti jasa akuntan publik, penilai, konsultan hukum, konsultan pajak, notaris, biaya pembuatan dan distribusi prospektus, biaya registrasi dan lainnya. Modal kerja berupa dana kas di DIRE Ciputra disiapkan sebesar kurang lebih $0,1 \%$ dari harga transaksi. 
- Tidak ada pinjaman dalam DIRE Ciputra. Dana berasal dari 51\% CTRA dan 49\% masyarakat tanpa pinjaman.

- Tarif perpajakan yang berlaku untuk analisis DIRE Ciputra ini adalah sebagai berikut: (i) Bea Perolehan Hak atas Tanah dan Bangunan (BPHTB) sebesar 5\% dari harga transaksi; (ii) Pajak Pertambahan Nilai (PPN) sebesar 10\% dari harga transaksi; (iii) Pajak Penghasilan atas pengalihan hak atas tanah dan atau bangunan (PPh Final) sebesar 0,5\% dari harga transaksi.

Skema keuangan penerbitan DIRE Ciputra yang digunakan dalam penelitian ini tertuang dalam gambar di bawah sebagai berikut:

$$
\text { Investor DIRE Ciputra }
$$

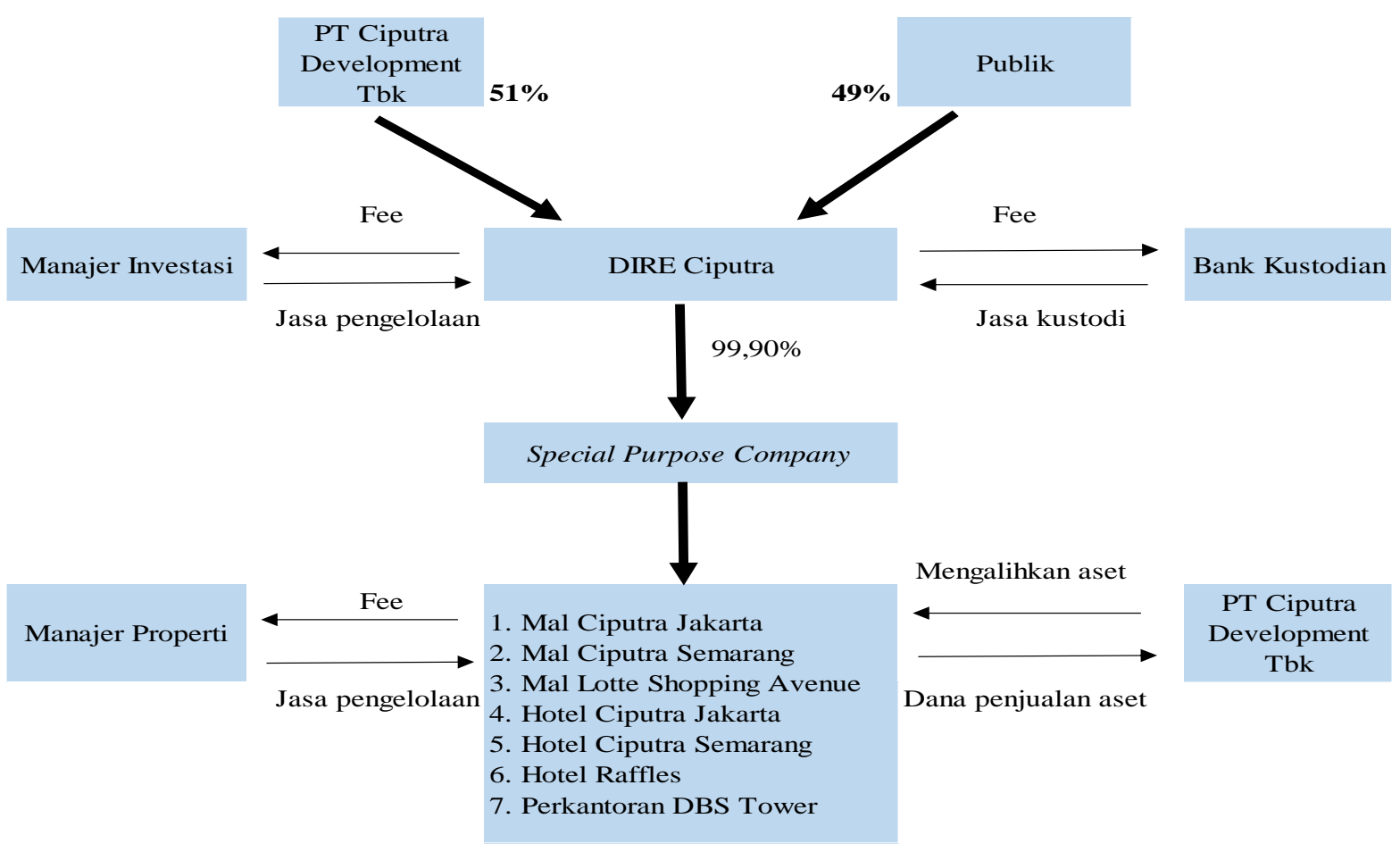

\section{ANALISIS DAN HASIL}

Hasil pengolahan data adalah sebagai berikut:

Data Keuangan - DIRE Ciputra

(Dalam Jutaan Rupiah)

Jumlah

Net Property Income (NPI) setelah pajak

542.278

Biaya Manajer Investasi

Biaya Manajer Properti

Biaya Bank Kustodian

Distributable Income

476.051 


\section{Penawaran Umum DIRE Ciputra}

(Dalam jutaan Rupiah)

\begin{tabular}{|c|c|c|c|c|c|}
\hline Sumber & $\mathbf{R p}$ & $\%$ & Penggunaan & $\mathbf{R p}$ & $\%$ \\
\hline CTRA & 5.657 .855 & $51 \%$ & Pembelian Aset & 9.495 .077 & $86 \%$ \\
\hline \multirow[t]{4}{*}{ Masyarakat } & 5.435 .978 & $49 \%$ & ВРНТВ $(5 \%)$ & 474.754 & $4 \%$ \\
\hline & & & PPN (10\%) & 949.508 & $9 \%$ \\
\hline & & & Modal Kerja & 9.495 & $0 \%$ \\
\hline & & & Biaya IPO & 165.000 & $1 \%$ \\
\hline Total & 11.093 .834 & $100 \%$ & Total & 11.093 .834 & $100 \%$ \\
\hline
\end{tabular}

Hasil analisis kinerja keuangan CTRA dari penerbitan DIRE Ciputra ini adalah sebagai berikut:

- CTRA memperoleh Rp 9.4 Triliun atas pengalihan aset-aset tersebut. Atas hasil penjualan tersebut dikenakan pajak penghasilan final atas pengalihan hak atas tanah dan atau bangunan sebesar 0,5\% dari harga jual tersebut yaitu sebesar Rp 47 Miliar. CTRA juga harus menyetor modal ke DIRE Ciputra untuk $51 \%$ unit penyertaan sebesar Rp 5.6 Triliun sehingga dana bersih yang diterima CTRA setelah dikurangi setoran modal ke DIRE Ciputra dan PPh Final atas penjualan aset adalah Rp 3.7 Triliun.

- Dividen yang diterima oleh CTRA tiap tahun adalah sebesar 51\% dari distributable income. Jika menggunakan angka tahun buku 2017, maka CTRA akan memperoleh dividen dari DIRE Ciputra sebesar Rp 242,7 Miliar (51\% x Rp 476 Miliar).

- Rasio solvabilitas yang terdiri dari debt to equity ratio (DER) dan debt ratio menjadi lebih baik sesudah penerbitan DIRE Ciputra. Rasio ini dihitung dengan menggunakan asumsi bahwa seluruh dana bersih yang diterima CTRA sebesar Rp 3,7 Triliun digunakan untuk melunasi pinjamannya. DER dan Debt Ratio dari $49 \%$ dan $24 \%$ menjadi masing-masing 18\% dan 11\% sesudah penerbitan DIRE Ciputra.

\begin{tabular}{|c|c|c|c|}
\hline (Dalam Jutaan Rupiah) & $\begin{array}{c}\text { Sebelum } \\
\text { Audit } 2017\end{array}$ & $\begin{array}{l}\text { Pro-Forma } \\
\text { Penyesuian }\end{array}$ & $\begin{array}{c}\text { Sesudah } \\
\text { Pro-Forma }\end{array}$ \\
\hline Total Aset & 31.706 .163 & 1.596 .019 & 33.302 .182 \\
\hline \multicolumn{4}{|c|}{ Pinjaman Bank, Obligasi dan } \\
\hline Wesel Bayar & 7.557 .905 & $(3.789 .746)$ & 3.768 .159 \\
\hline Ekuitas & 15.450 .765 & 5.385 .766 & 20.836 .531 \\
\hline
\end{tabular}

$\begin{array}{lll}\text { Rasio Solvabilitas } & & \\ \text { DER } & 49 \% & 18 \% \\ \text { Debt Ratio } & 24 \% & 11 \%\end{array}$

\section{KESIMPULAN}

Kinerja keuangan PT Ciputra Development Tbk (CTRA) menjadi semakin baik akibat dari penerbitan DIRE. Dana bersih yang didapat dari penerbitan DIRE tersebut adalah Rp 3.7 Triliun. Dana tersebut dapat digunakan oleh CTRA untuk ekspansi dalam membangun proyek-proyek lainnya dan atau untuk membayar seluruh atau sebagian pinjaman bank. Dana tersebut jika digunakan untuk melunasi pinjaman bank maka akan membuat rasio solvabilitias menjadi lebih sehat atau lebih baik. Rasio solvabilitas yang rendah menunjukkan kondisi keuangan CTRA yang sangat sehat dan dapat memiliki room for growth untuk proyek-proyek baru yang didanani dengan pinjaman baru. 


\section{DAFTAR PUSTAKA}

Brueggeman, William B. and Fisher, Jeffrey D. (2016). Real Estate Finance and Investments. New York: McGraw-Hill Education.

Ciptadana Asset Management. (2012). Prospektus DIRE Ciptadana Properti Ritel Indonesia. Hung, Chian Yat, Joinkey, So Chun-Kei and Sin, Tang Bo. (2008). Time-Varying Performance Of Four Asia-Pacific REITs. Journal of Property Investment \& Finance, 26 (3), 210-231.

Jayaraman, Bobby. (2014). Building Wealth Through REITS. Singapore : Marshall Cavendish Business.

Kelly, Stephanie Krewson and Thomas, R. Brad. (2016). The Intelligent REIT Investor: How to Build Wealth With Real Estate Investment Trusts. New Jersey: John Wiley \& Sons, Inc.

Leong, Kaiwen, Tan, Wenyou, \& Leong, Elaine. (2014). International REITS: How to Invest Overseas and Build An International Portfolio. Singapore : Marshall Cavendish Business.

Lim, Aileen. (2011). Peran Notaris Dalam Pelaksanaan REITs (Real Estate Investment Trust)/DIRE-KIK (Dana Investasi Real Estat - Kontrak Investasi Kolektif) di Indonesia. Tesis. Depok : Fakultas Hukum Universitas Indonesia Program Studi Magister Kenotariatan.

Ooi, Joseph T.L., Newell, Graeme and Sing, Tien-Foo. (2006). The Growth of REIT Markets in Asia. Journal of Real Estate Literature, 14 (2), 203-222. 
